\title{
Medicinal Compounds form Traditional Herbs
}

\section{Song Gao*}

Department of Pharmacological and Pharmaceutical Sciences, The University of Houston, Texas, USA

\section{Editor's Note}

Natural Products Chemistry is a sub-branch of chemistry that mainly focuses on the identification of bioactive natural products from herbals, marine plants, or microorganism. Natural Products Chemistry \& Research is an open access peer-reviewed international journal that publishes articles related to all the aspects of natural products. The current issue (volume No 4, issue 4) published two full-reviews, one mini review, and five research articles.

In one of the research articles, Sharma et al. reported activities evaluation of the extracts of different parts of Tinospora cordifolia [1]. Another research article that published by Williams et al. reported the antioxidant activity of Leonotis nepetifolia extracts in protecting APAP-induced hepatic injuries and its role in modulating the antioxidant enzyme activities. In this article, the authors found that the anti-oxidative efficacy of the above extract is related to free radical scavengers, which reduces the super oxide dismutase activity [2]. In Alberto's research article, the authors evaluated potential activity of some traditional medicinal plants in the genus of Rumexspp [3]. Another article reported by Ali was trying to optimize the dyeing and extraction conditions of marigold colorant by using a central composite design approach. The last research article published by Ijeh reported the amino acid and nutritional profile of wild Termitomycesrobustus $[4,5]$.

For the review articles, Rehman et al. discussed the importance of aromatic plants in synthesizing essential oils [6] and Fazary et al. analyzed the survey outcome of bioactive Lignans on their chemical
Structures [7]. Finally, Getasetegn et al. discussed the valuable compounds and their biological activities present in some Medicinal Plants [8].

\section{References}

1. Sharma A, Batra A (2016) Primary Metabolite Profiling of Tinosporacordifolia. Nat Prod Chem Res 4: 221

2. Williams AF, Clement YN, Nayak SB, Rao AVC (2016) Leonotisnepetifolia Protects against Acetaminophen-Induced Hepatotoxicity: Histological Studies and the Role of Antioxidant Enzymes. Nat Prod Chem Res 4: 222.

3. Jerezano Alberto VD, Ríos Saúl A, Tepancal-Gomez E, Salas-Mendosa E, Villanueva L, et al. (2016) Some Traditional Medicinal Plants of North Region from Puebla, Mexico: Uses and Potential Pharmacological Activity of Rumex spp. Nat Prod Chem Res 4: 223.

4. Ali S, Noor S, Siddiqua UH, Jabeen S, Hussain T (2016) Central Composite Design Approach for Optimization of Extraction and Dyeing Conditions of Marigold Colorant. Nat Prod Chem Res 4: 224

5. Ijeh II, Eke IN, Ugwu CC, Ejike ECCC (2016) Myco-Nourishment from the Wild: Chemical Analyses of the Nutritional and Amino Acid Profile of Termitomycesrobustus Harvested from Uzuakoli, Nigeria. Nat Prod Chem Res 4: 225.

6. Rehman R, Hanif MA, Mushtaq Z, Mochona B, Qi X (2016) Biosynthetic Factories of Essential Oils: The Aromatic Plants. Nat Prod Chem Res 4: 227.

7. Fazary AE, Alfaifi MY, Saleh KA, Alshehri MA, Elbehairi SEI (2016) Bioactive Lignans: A Survey Report on their Chemical Structures? Nat Prod Chem Res 4: 226.

8. Getasetegn M, Tefera Y (2016) Biological Activities and Valuable Compounds from Five Medicinal Plants. Nat Prod Chem Res 4: 220. 